\title{
Maternal Support Is Protective Against Suicidal Ideation Among a Diverse Cohort of Young Transgender Women
}

\author{
Harry Jin, PhD, MPH, ${ }^{1, *}$ Arjee Restar, PhD, MPH, ${ }^{2, *}$ William C. Goedel, PhD, \\ Adedotun Ogunbajo, PhD, MPH, MHS, ${ }^{2}$ Katie Biello, PhD, MPH, ${ }^{1,2}$ Don Operario, PhD, MS, ${ }^{2}$ Lisa Kuhns, PhD, ${ }^{3}$ \\ Sari L. Reisner, ScD, MA, ${ }^{4}$ Robert Garofalo, MD, MPH, ${ }^{5}$ and Matthew J. Mimiaga, ScD, MPH ${ }^{1,2}$
}

\begin{abstract}
Purpose: We assessed if young transgender women (YTW) with parents who are supportive of their transgender identity had lower odds of having suicidal ideation compared with YTW with unsupportive parents.

Methods: This study analyzed baseline findings from a diverse sample of 297 sexually active, YTW 16-29 years of age who were enrolled in Project LifeSkills, a randomized controlled HIV prevention intervention efficacy trial in Chicago and Boston, between 2012 and 2015. Bivariate and multivariable logistic regression were used to assess if parental support was associated with a decreased odds of suicidal ideation.

Results: Nearly one-fifth (18.9\%) of YTW reported suicidal ideation at baseline. In our adjusted multivariable model, YTW with supportive mothers had 0.37 (95\% confidence interval $=0.15-0.90)$ times the odds of having suicidal ideation compared with YTW with unsupportive mothers.

Conclusion: This study found that the odds of suicidal ideation were lower among YTW who had mothers who were supportive of their transgender identity. Our results suggest that parent-focused interventions to improve the relationships between YTW and their parents may lower the odds of YTW having suicidal ideation.

Clinical Trial Registration Identifier: NCT01575938
\end{abstract}

Keywords: young transgender women, parental support, suicidal ideation, mental health

\section{Introduction}

$\mathbf{T}$ RANSGENDER YOUTH AND YOUNG ADULTS represent a vulnerable population at risk for negative mental and behavioral health outcomes, including depression and frequent psychological distress. ${ }^{1-3}$ In particular, rates of suicidal ideation and attempt are alarmingly high among transgender youth. ${ }^{4}$ In a population-based survey of high school students in California, transgender youth were nearly twice as likely to report suicidal ideation in the past year compared with their nontransgender peers. ${ }^{5}$ Moreover, in a survey of more than 25,000 transgender respondents conducted in 2015 across the United States, 40\% reported having attempted suicide in their lifetime. ${ }^{6}$ This statistic is nine times higher than the attempted suicide rate among the general U.S. population (4.6\%). ${ }^{6}$ In addition, $7 \%$ of transgender respondents reported attempting suicide in the past year, with 18-25-year-old respondents being the age group with the highest rate of attempts $(10 \%){ }^{6}$ Findings from these studies highlight the vulnerability of transgender youth to experiencing poor mental health outcomes.

Families may play a vital role in protecting against negative psychosocial outcomes among transgender youth and young adults. Extensive research has focused on the nurturing and protective role of families in the health and wellbeing of youth and young adults. ${ }^{7}$ In general, strong connections to family have been shown to be protective against major risk behaviors. In a landmark study using data from the National Longitudinal Study of Adolescent Health, family connectedness was protective against emotional distress, suicidal thoughts and behaviors, violence, substance use, and early sexual debut among adolescents. ${ }^{8}$ A growing literature has explored the role that family relationships may play in supporting positive health outcomes for sexual minority youth and young adults. ${ }^{9}$ In a sample of lesbian, gay, and bisexual (LGB) young adults, for example, higher levels of family

Departments of ${ }^{1}$ Epidemiology and ${ }^{2}$ Behavioral and Social Sciences, Brown University School of Public Health, Providence, Rhode Island, USA.

${ }^{3}$ Department of Pediatrics, Feinberg School of Medicine, Northwestern University, Chicago, Illinois, USA.

${ }^{4}$ Division of General Pediatrics, Boston Children's Hospital and Harvard Medical School, Boston, Massachusetts, USA.

${ }^{5}$ Division of Adolescent and Young Adult Medicine, Ann \& Robert H. Lurie Children's Hospital of Chicago, Chicago, Illinois, USA.

*Contributed equally. 
rejection during adolescence were associated with higher odds of attempted suicide, ${ }^{10}$ while in a sample of LGBT young adults higher levels of family acceptance were protective. ${ }^{11}$ In a sample of transgender youth, one study found that parental support was associated with higher life satisfaction and lower depressive symptoms. ${ }^{12} \mathrm{~A}$ study of transgender youth in Canada found that family connectedness was associated with lower rates of mental health problems. ${ }^{13}$

While several studies have examined the impact of parental support on the mental health of transgender youth, ${ }^{12,14,15}$ we are unaware of studies that have examined how maternal and paternal support may affect the risk of suicidal ideation differently. To better understand this relationship, we assessed if maternal and paternal knowledge and support of their child's transgender identity was associated with a history of suicidal ideation among a diverse multicity cohort of young transgender women (YTW) in the United States. We hypothesized that YTW who have mothers or fathers who are supportive of their gender identity are at lower odds of having suicidal ideation compared with YTW who have mothers or fathers who are unsupportive.

\section{Methods}

\section{Study sample}

YTW were recruited in Chicago, Illinois and Boston, Massachusetts between 2012 and 2015 to participate in Project LifeSkills, an efficacy trial of a culturally specific, empowerment-based, and group-delivered behavioral prevention intervention to reduce sexual risk for HIV acquisition and transmission in sexually active YTW 16-29 years of age. ${ }^{16,17}$ Participants were recruited using multiple convenience sampling strategies, recruiting at community-based organizations, bars, clubs, and through social media advertisements (e.g., Facebook, Craigslist). Eligible participants were (1) 16-29 years of age; (2) assigned male sex at birth and at enrollment identified as a woman, female, transgender woman, or another gender identity on the trans-feminine spectrum (e.g., male to female, transsexual woman); (3) spoke English; (4) and self-reported engaging in any condomless anal or vaginal sex. Of the 300 YTW enrolled, 297 responded to questions regarding suicidal ideation and parental acceptance/knowledge of their gender identity and were included in this analysis. All participants provided written informed consent with parental consent waived for those under the age of 18, and the Institutional Review Boards at both study sites, Ann \& Robert H. Lurie Children's Hospital of Chicago and the Fenway Institute, approved the study.

\section{Study procedure}

Enrolled study participants of Project LifeSkills completed study assessments at baseline, 6, 12, 18, and 24 months. After completing the baseline survey, the participants were randomized into the intervention or control study arm, which have been described in detail elsewhere. ${ }^{17}$ This study analyzed only the baseline data.

\section{Measures}

Demographic characteristic data (i.e., recruitment site, age, race, education, and sexual orientation) were collected at all study assessments. Participants were asked "What is your date of birth?" which was then used to determine age by calcu- lating the days between their birth date and the day they completed their study assessments. Participants were also asked "What do you consider to be your primary race or ethnic background?" and they could choose "White," "Black/ African American," "Spanish/Hispanic/Latino/a," "Asian," "American Indian/Alaskan Native," "Native Hawaiian or Other Pacific Islander," or "other." Responses were then recategorized to one of the four categories: "White," "Black," "Latina," or "Other." They were also asked "What is your highest level of education?" and participants could choose "less than 8th grade," "8th grade," "some high school," "GED," "high school diploma," "trade school certificate," "some college," "undergraduate degree," "some graduate school," or "graduate degree." Those who chose one of the first five options were recategorized as "high school or less," and those who chose one of the last five options were recategorized as "some college or higher." Participants were also asked "How do you describe your sexual identity?" and they could choose between "gay/homosexual," "lesbian," "bisexual," "heterosexual," or "other."

The outcome of interest for this analysis is self-reported suicidal ideation. Participants were asked, "Do you think about suicide?" to which they could respond "yes" or "no."

The exposure of interest is whether or not the participant has parents who are aware and accepting of their gender identity. The exposure variable was derived from two survey questions and has four categories: (1) supportive, (2) not supportive, (3) participant's mother is unaware of their gender identity, and (4) no mother figure. The following three paragraphs outline how we derived the exposure variable for maternal support. The same process was used to derive the variable for paternal support.

Participants were first asked "Have you told your mother, or the woman who raised you and who you thought of as your mother, that you are transgender?," to which participants responded by choosing between the options, "I don't have such a person in my life," "No, I haven't told my mother and she doesn't know about my gender status," "No, I haven't told my mother, but she knows or probably knows about my gender status," and "Yes, I told my mother about my gender status." Participants were then asked, "What is your mother's response to your gender status now?" to which participants responded by choosing between the options, "accepting," "tolerant," "intolerant," and "rejecting."

If a participant told their mother about their gender identity and indicated that their mother is either accepting or tolerant of it, the participant was categorized as having a mother who is "supportive" of their gender identity. If a participant told their mother about their gender identity and indicated that their mother is intolerant or rejecting of it, the participant was categorized as having a mother who is "not supportive" of their gender identity. If the participant chose either "No, I haven't told my mother and she doesn't know about my gender status" or "No, I haven't told my mother, but she knows or probably knows about my gender status" as their response to the first question, they were categorized as "participant's mother is unaware of their gender identity." Participants were categorized as having "no mother figure" if they chose "I don't have such a person in my life" as their response to the first question.

Those who chose "No, I haven't told my mother, but she knows or probably knows about my gender status" in response 
to the first question were considered to have mothers without knowledge of their gender identity because they never explicitly spoke to their mothers about their gender identity.

Lifetime sex work was assessed by asking participants "Have you ever traded sexual activity or favors for food, money, a place to sleep, drugs, or other material goods? (yes/no)." Lifetime homelessness was assessed by asking participants "In your lifetime, have you ever been homeless at all? (yes/no)." Participants were asked "Do you have a mental health care provider, for example, a therapist, psychologist, psychiatrist, or counselor that you see for mental health services? (yes/no)." Participants were also asked "Was there a time in the past 12 months when you needed to see a mental health care provider, but could not because of cost? (yes/no)," as well as "Have you ever had any problems getting mental health care because of your gender identity or gender presentation? (yes/no)."

\section{Statistical analyses}

We compared demographic characteristics (e.g., age, race, education), social marginalization indicators (e.g., history of sex work, lifetime homelessness), and mental health care indicators (e.g., has a mental health care provider, did not see a mental health care provider because of cost in the past 12 months) among those who self-reported having versus not having suicidal ideation. Bivariate analyses were conducted using $\chi^{2}$ tests for categorical variables and $t$-tests for continuous variables. Finally, we used bivariate and multivariable logistic regressions to calculate the odds of having suicidal ideation. We selected variables to include in the multivariable logistic regression model based on a priori assumptions about the association between parental support and mental health outcomes. ${ }^{18,19}$ All statistical analyses were conducted in SAS 9.4 (SAS Institute Inc., Cary, NC).

\section{Sensitivity analysis}

A sensitivity analysis was conducted in which YTW who chose "No, I haven't told my mother/father, but she/he knows or probably knows about my gender status" were removed from the sample set ( 38 removed). The sensitivity analysis employed the same methods described in the "Statistical Analyses" section. This approach was used to address the potential for misclassification bias since we were not certain that the parents of these YTW were aware of their gender identity.

\section{Results}

\section{Sample characteristics}

Study sample characteristics are reported in Table 1 . The mean age of the 297 YTW included in this analysis was 23.2 (standard deviation $=3.50$ ) and nearly half of the sample was Black $(48.8 \%)$ and a quarter was White $(25.6 \%)$. Fifty-six (18.9\%) YTW reported having suicidal ideation. More than half of the sample reported that their mother was supportive of their gender identity, whereas $30.3 \%$ reported that their father was supportive.

\section{Bivariate analyses}

In the bivariate analyses, YTW who were older (odds ratio $[\mathrm{OR}]=1.11$, 95\% confidence interval $[\mathrm{CI}]=1.02-1.21$ ), re- ceived more formal education $(\mathrm{OR}=2.01,95 \% \mathrm{CI}=1.12$ 3.61 ), did not see a mental health care provider because of cost in the past 12 months $(\mathrm{OR}=2.29,95 \% \mathrm{CI}=1.22-4.32)$, and experienced problems receiving mental health care due to their gender identity or presentation $(\mathrm{OR}=3.03,95 \%$ $\mathrm{CI}=1.34-6.85)$ had greater odds of having suicidal ideation (Table 2). Compared with Black YTW, White YTW had greater odds of having suicidal ideation $(\mathrm{OR}=2.56,95 \%$ $\mathrm{CI}=1.31-5.02)$. YTW whose mothers were supportive of their gender identity had significantly lower odds $(\mathrm{OR}=0.32$, 95\% $\mathrm{CI}=0.15-0.68)$ of having suicidal ideation compared with YTW with unsupportive mothers. Our sensitivity analysis produced results that were very similar to those of the main analysis (Table 3).

\section{Multivariable analysis}

The multivariable logistic regression reported in Table 2 included recruitment site, age, race, education, sexual orientation, mother's knowledge/support, father's knowledge/support, lifetime sex work, lifetime homelessness, has a mental health care provider, did not see a mental health care provider because of cost in the past 12 months, and experienced problems receiving mental health care due to their gender identity or presentation. In this model, those who had experienced homelessness had more than twice the odds of having suicidal ideation compared with those who had not experienced homelessness (adjusted odds ratio $[\mathrm{aOR}]=2.16,95 \% \mathrm{CI}=1.03-4.53)$. White YTW had significantly greater odds of having suicidal ideation compared with Black YTW $(\mathrm{aOR}=2.58,95 \% \mathrm{CI}=1.02-6.50)$. YTW with mothers who were supportive of their gender identity had nearly one-third the odds of having suicidal ideation compared with those with unsupportive mothers $(\mathrm{aOR}=0.37$, 95\% CI $=0.15-0.90$ ). A father's knowledge and/or support of their child's transgender identity was not associated with suicidal ideation.

\section{Discussion}

This study highlights the relationship between parental knowledge and support of transgender identity and YTW's suicidal ideation. Specifically, the results of this study show that the odds of suicidal ideation were significantly lower among YTW who perceived their mothers to be supportive of their transgender identity. To the best of our knowledge, this study is among the first to disentangle maternal and paternal support and its effect on YTW, and provides nuance to the existing literature that examines the determinants of suicidal ideation and other negative mental health outcomes (e.g., serious psychological distress, depression, and poor quality of mental health) that are consistently documented at high rates in studies of transgender women. ${ }^{6,20,21}$

As parents are key agents in shaping children and adolescents' development, ${ }^{22}$ it is not surprising that perceived negative experiences such as being unsupportive of their child's transgender identity would be linked to higher negative mental health outcomes such as having suicidal ideation. However, transgender women begin their gender identity developmental milestones early on in life (e.g., being aware of and disclosing their transgender identity to others). ${ }^{23}$ As a result, they are more prone to experiencing transphobia from other agents with whom they interact early in life (e.g., friends, classmates, teachers) whose influence can impact them throughout later 
Table 1. Sociodemographic Characteristics, Parental Knowledge and Support, Social Marginalization, and Mental Health Indicators Among a Diverse Cohort of Young Transgender Women $(N=297)$

\begin{tabular}{|c|c|c|c|c|}
\hline & $\begin{array}{c}\text { Total } \\
(\mathrm{n}=297)\end{array}$ & $\begin{array}{c}\text { "Do you think } \\
\text { about suicide?", } \\
\text { No }(\mathrm{n}=241)\end{array}$ & $\begin{array}{c}\text { "Do you think } \\
\text { about suicide?"' } \\
\text { Yes }(\mathrm{n}=56)\end{array}$ & $\mathrm{p}$ Value \\
\hline Site & & & & 0.2533 \\
\hline Boston & $144(48.5)$ & $113(46.9)$ & $31(55.36)$ & \\
\hline Chicago & $153(51.5)$ & $128(53.1)$ & $25(44.64)$ & \\
\hline \multicolumn{5}{|l|}{ Demographics } \\
\hline Age & & & & 0.0126 \\
\hline Mean (SD) & $23.2(3.50)$ & $23.1(3.6)$ & $24.4(3.1)$ & \\
\hline Race & & & & 0.0295 \\
\hline White & $76(25.6)$ & $53(22.0)$ & $23(41.1)$ & \\
\hline Black & $145(48.8)$ & $124(51.5)$ & $21(37.5)$ & \\
\hline Latina & $37(12.5)$ & $32(13.3)$ & $5(8.9)$ & \\
\hline $\begin{array}{l}\text { Other/mixed race (e.g., American Indian, Asian, } \\
\text { Pacific Islander) }\end{array}$ & $39(13.1)$ & $32(13.3)$ & $7(12.5)$ & \\
\hline Education & & & & 0.0187 \\
\hline High school or less & $174(58.6)$ & $149(61.8)$ & $25(44.6)$ & \\
\hline Some college or higher & $123(41.4)$ & $92(38.2)$ & $31(55.4)$ & \\
\hline Sexual orientation & & & & 0.5361 \\
\hline Bisexual & $58(19.5)$ & $45(18.7)$ & $13(23.2)$ & \\
\hline Gay/homosexual & $79(26.6)$ & $69(28.6)$ & $10(17.9)$ & \\
\hline Heterosexual & $116(39.1)$ & $92(38.2)$ & $24(42.9)$ & \\
\hline Lesbian & $16(5.4)$ & $12(5.0)$ & $4(7.1)$ & \\
\hline Other sexual orientation/not listed & $28(9.4)$ & $23(9.5)$ & $5(8.9)$ & \\
\hline \multicolumn{5}{|c|}{ Parental knowledge/acceptance of child's gender identity } \\
\hline Mother's knowledge/acceptance & & & & 0.0086 \\
\hline Supportive & $163(54.9)$ & $136(56.4)$ & $27(48.2)$ & \\
\hline Not supportive & $39(13.1)$ & $24(10.0)$ & $15(26.8)$ & \\
\hline Does not know about her child's gender identity & $54(18.2)$ & $47(19.5)$ & $7(12.5)$ & \\
\hline No mother figure & $41(13.8)$ & $34(14.1)$ & $7(12.5)$ & \\
\hline Father's knowledge/acceptance & & & & 0.0242 \\
\hline Supportive & $90(30.3)$ & $75(31.1)$ & $15(26.8)$ & \\
\hline Not supportive & $43(14.5)$ & $31(12.9)$ & $12(21.4)$ & \\
\hline Does not know about his child's gender identity & $64(21.6)$ & $59(24.5)$ & $5(8.9)$ & \\
\hline No father figure & $100(33.7)$ & $76(31.5)$ & $24(42.9)$ & \\
\hline \multicolumn{5}{|l|}{ Social marginalization } \\
\hline Lifetime sex work & & & & 0.3300 \\
\hline No & $150(50.5)$ & $125(51.9)$ & $25(44.6)$ & \\
\hline Yes & $147(49.5)$ & $116(48.1)$ & $31(55.4)$ & \\
\hline Lifetime homelessness & & & & 0.0548 \\
\hline No & $151(50.8)$ & $129(53.5)$ & $22(39.3)$ & \\
\hline Yes & $146(49.2)$ & $112(46.5)$ & $34(60.7)$ & \\
\hline \multicolumn{5}{|l|}{ Mental health care indicators } \\
\hline Has a mental health care provider & & & & 0.7427 \\
\hline No & $186(62.6)$ & $152(63.1)$ & $34(60.7)$ & \\
\hline Yes & $111(37.4)$ & $89(36.9)$ & $22(39.3)$ & \\
\hline \multicolumn{4}{|c|}{ Did not see a mental health care provider because of cost in the past 12 months } & 0.0089 \\
\hline No & $230(77.4)$ & $194(80.5)$ & $36(64.3)$ & \\
\hline Yes & $67(22.6)$ & $47(19.5)$ & $20(35.7)$ & \\
\hline \multicolumn{4}{|c|}{ Experienced problems receiving mental health care due to their gender identity or presentation } & 0.0057 \\
\hline No & $268(90.2)$ & $223(92.5)$ & $45(80.4)$ & \\
\hline Yes & $29(9.8)$ & $18(7.5)$ & $11(19.6)$ & \\
\hline
\end{tabular}

$\mathrm{SD}$, standard deviation.

stages of their development. Therefore, it is possible that perceived unsupportiveness from friends, classmates, and teachers during a time when transgender women disclose their gender identity to their parents could play a vital role and impact their mental health more so than from other agents.

We recommend that more research be conducted to understand how the timing of such disclosures and potential parental- focused interventions could mitigate parents' unsupportiveness and other transphobic interactions. Our results corroborate those of other studies related to the impact of parental support on the mental health of sexual and gender minority youth. ${ }^{18,24,25}$ These studies all reported that social inclusion (e.g., support from peers, parents, mentors) was associated with better mental health outcomes. Interventions designed to improve 
Table 2. Correlates of Suicidal Ideation Among a Diverse Cohort of Young Transgender Women $(N=297)$

\begin{tabular}{|c|c|c|c|c|}
\hline & $\begin{array}{l}\text { Unadjusted } O R \\
(95 \% \text { CI })\end{array}$ & p Value & $\begin{array}{c}a O R s \\
(95 \% C I)\end{array}$ & p Value \\
\hline \multicolumn{5}{|l|}{ Site } \\
\hline Boston & $1.41(0.78-2.52)$ & 0.2546 & $0.97(0.42-2.24)$ & 0.9344 \\
\hline Chicago & - & - & - & - \\
\hline \multicolumn{5}{|l|}{ Demographics } \\
\hline \multicolumn{5}{|l|}{ Age } \\
\hline Mean (SD) & $1.11(1.02-1.21)$ & 0.0138 & $1.05(0.95-1.17)$ & 0.3555 \\
\hline \multicolumn{5}{|l|}{ Race } \\
\hline White & $2.56(1.31-5.02)$ & 0.0062 & $2.58(1.02-6.50)$ & 0.0453 \\
\hline Black & - & - & - & - \\
\hline Latina & $0.92(0.32-2.64)$ & 0.8805 & $0.99(0.31-3.19)$ & 0.9807 \\
\hline $\begin{array}{l}\text { Other/mixed race (e.g., American Indian, } \\
\text { Asian, Pacific Islander) }\end{array}$ & $1.29(0.51-3.31)$ & 0.5934 & $1.54(0.55-4.34)$ & 0.4162 \\
\hline \multicolumn{5}{|l|}{ Education } \\
\hline High school or less & - & - & - & - \\
\hline Some college or higher & $2.01(1.12-3.61)$ & 0.0200 & $1.48(0.55-4.34)$ & 0.2820 \\
\hline \multicolumn{5}{|l|}{ Sexual orientation } \\
\hline Bisexual & $1.11(5.22-2.38)$ & 0.7934 & $0.80(0.33-1.95)$ & 0.6293 \\
\hline Gay/homosexual & $0.56(0.25-1.24)$ & 0.1504 & $0.54(0.21-1.37)$ & 0.1966 \\
\hline Heterosexual & - & - & - & - \\
\hline Lesbian & $1.28(0.38-4.32)$ & 0.6931 & $0.76(0.18-3.22)$ & 0.7110 \\
\hline Other sexual orientation/not listed & $0.83(0.29-2.42)$ & 0.7375 & $0.53(0.16-1.81)$ & 0.3126 \\
\hline \multicolumn{5}{|l|}{ Parental knowledge/support of child's gender identity } \\
\hline \multicolumn{5}{|l|}{ Mother's knowledge/support } \\
\hline Supportive & $0.32(0.15-0.68)$ & 0.0033 & $0.37(0.15-0.90)$ & 0.0277 \\
\hline Not supportive & - & - & - & - \\
\hline Does not know about her child's gender identity & $0.24(0.09-0.66)$ & 0.0060 & $0.56(0.16-1.95)$ & 0.3583 \\
\hline No mother figure & $0.33(0.12-0.93)$ & 0.0361 & $0.23(0.07-0.78)$ & 0.0185 \\
\hline \multicolumn{5}{|l|}{ Father's knowledge/acceptance } \\
\hline Supportive & $0.52(0.22-1.23)$ & 0.1354 & $0.77(0.29-2.06)$ & 0.5965 \\
\hline Not supportive & - & - & - & - \\
\hline Does not know about his child's gender identity & $0.22(0.07-0.68)$ & 0.0084 & $0.36(0.09-1.42)$ & 0.1428 \\
\hline No father figure & $0.82(0.36-1.83)$ & 0.6219 & $1.56(0.57-4.32)$ & 0.3895 \\
\hline \multicolumn{5}{|l|}{ Social marginalization } \\
\hline \multicolumn{5}{|l|}{ Lifetime sex work } \\
\hline No & - & - & - & - \\
\hline Yes & $1.34(0.75-2.40)$ & 0.3310 & $1.13(0.54-2.35)$ & 0.7505 \\
\hline \multicolumn{5}{|l|}{ Lifetime homelessness } \\
\hline No & - & - & - & - \\
\hline Yes & $1.78(0.98-3.22)$ & 0.0567 & $2.16(1.03-4.53)$ & 0.0428 \\
\hline \multicolumn{5}{|l|}{ Mental health care indicators } \\
\hline \multicolumn{5}{|l|}{ Has a mental health care provider } \\
\hline No & - & - & - & - \\
\hline Yes & $1.11(0.61-2.01)$ & 0.7427 & $0.67(0.33-1.36)$ & 0.2627 \\
\hline \multicolumn{5}{|c|}{ Did not see a mental health care provider because of cost in the past 12 months } \\
\hline No & - & - & - & - \\
\hline Yes & $2.29(1.22-4.32)$ & 0.0101 & $1.58(0.73-3.42)$ & 0.2474 \\
\hline \multicolumn{5}{|c|}{ Experienced problems receiving mental health care due to their gender identity or presentation } \\
\hline No & - & - & - & - \\
\hline Yes & $3.03(1.34-6.85)$ & 0.0078 & $2.19(0.87-5.54)$ & 0.0983 \\
\hline
\end{tabular}

aORs, adjusted odds ratios; CI, confidence interval; OR, odds ratio.

family cohesion and promote understanding between parents and their transgender children may result in substantial reductions in suicidal ideation. ${ }^{25}$

Our study found that maternal and paternal support might have a different effect on the odds of YTW exhibiting suicidal ideation. There are currently very few studies that have explored differences in the relationships that YTW have with their mothers and fathers, ${ }^{26-28}$ and to the best of our knowledge, there are no articles specifically examining how these differences may affect mental health outcomes among transgender youth. However, a qualitative study discovered differences with respect to the parents' motivations to understand and participate in their children's lives. ${ }^{28}$ This study, which was conducted in Japan, found that transgender children were more comfortable disclosing their gender identity to their mothers, and that their mothers were more eager to understand their lived experiences, as well as other issues pertaining to the broader transgender community. 
Table 3. Sensitivity Analysis-Correlates of Suicidal Ideation Among a Diverse Cohort of Young Transgender Women $(N=259)$

\begin{tabular}{|c|c|c|}
\hline & aORs $(95 \%$ CI $)$ & $\mathrm{p}$ Value \\
\hline \multicolumn{3}{|l|}{ Site } \\
\hline Boston & $0.95(0.40-2.25)$ & 0.9129 \\
\hline Chicago & - & \\
\hline \multicolumn{3}{|l|}{ Demographics } \\
\hline \multicolumn{3}{|l|}{ Age } \\
\hline Mean (SD) & $1.06(0.95-1.18)$ & 0.3106 \\
\hline \multicolumn{3}{|l|}{ Race } \\
\hline White & $2.61(1.01-6.76)$ & 0.0486 \\
\hline Black & & (2) \\
\hline Latina & $1.11(0.33-3.75)$ & 0.8672 \\
\hline Other/mixed race (e.g., American Indian, Asian, Pacific Islander) & $1.39(0.48-4.03)$ & 0.5459 \\
\hline \multicolumn{3}{|l|}{ Education } \\
\hline High school or less & - & - \\
\hline Some college or higher & $1.62(0.77-3.43)$ & 0.2051 \\
\hline \multicolumn{3}{|l|}{ Sexual orientation } \\
\hline Bisexual & $0.65(0.26-1.64)$ & 0.3591 \\
\hline Gay/homosexual & $0.45(0.17-1.21)$ & 0.1133 \\
\hline Heterosexual & - & - \\
\hline Lesbian & $0.43(0.09-2.12)$ & 0.2967 \\
\hline Other sexual orientation/not listed & $0.49(0.14-1.72)$ & 0.2660 \\
\hline \multicolumn{3}{|l|}{$\begin{array}{l}\text { Parental knowledge/support of child's gender identity } \\
\text { Mother's knowledge/sunnort }\end{array}$} \\
\hline \multicolumn{3}{|l|}{ Mother's knowledge/support } \\
\hline Supportive & $0.40(0.16-1.00)$ & 0.0510 \\
\hline Not supportive & & \\
\hline Does not know about her child's gender identity & $0.97(0.21-4.56)$ & 0.9700 \\
\hline No mother figure & $0.24(0.07-0.84)$ & 0.0258 \\
\hline \multicolumn{3}{|l|}{ Father's knowledge/acceptance } \\
\hline Supportive & $0.67(0.26-1.91)$ & 0.4842 \\
\hline Not supportive & - & - \\
\hline Does not know about his child's gender identity & $0.28(0.05-1.65)$ & 0.1602 \\
\hline No father figure & $1.54(0.54-4.39)$ & 0.4191 \\
\hline \multicolumn{3}{|l|}{ Social marginalization } \\
\hline \multicolumn{3}{|l|}{ Lifetime sex work } \\
\hline No & - & - \\
\hline Yes & $1.08(0.51-2.27)$ & 0.8499 \\
\hline \multicolumn{3}{|l|}{ Lifetime homelessness } \\
\hline No & - & - \\
\hline Yes & $1.91(0.89-4.12)$ & 0.0981 \\
\hline \multicolumn{3}{|l|}{ Mental health care indicators } \\
\hline \multicolumn{3}{|l|}{ Has a mental health care provider } \\
\hline No & - & - \\
\hline Yes & $0.52(0.25-1.11)$ & 0.0894 \\
\hline \multicolumn{3}{|c|}{ Did not see a mental health care provider because of cost in the past 12 months } \\
\hline $\begin{array}{l}\text { No } \\
\text { Yes }\end{array}$ & $1.74(0.78-3.91)$ & $0 . \overline{1780}$ \\
\hline \multicolumn{3}{|c|}{ Experienced problems receiving mental health care due to their gender identity or presentation } \\
\hline No & - & - \\
\hline Yes & $1.80(0.65-4.98)$ & 0.2563 \\
\hline
\end{tabular}

The researchers also found that there was more "emotional distance" between fathers and their children. ${ }^{28}$ Although research on this topic is limited, our study corroborates other studies' findings that the relationship transgender youth have with their mothers and fathers differs. More research is needed to understand the mechanisms through which maternal and/or parental support affects the mental health of their transgender children.

Our findings also revealed racial disparities in suicidal ideation between White and Black YTW. Specifically, we found that White YTW had greater odds of suicidal ideation compared with Black YTW. When contrasted with the existing literature on this topic both in the U.S. general ${ }^{29}$ and transgender populations, ${ }^{5,30}$ the findings are mixed, with some studies reporting no differences in risk of suicidal ideation between Black and White people ${ }^{5,31}$ and others reporting higher rates among White people. ${ }^{29,30}$ For example, one national study with U.S. transgender and gender-nonconforming adults $(n=816)$ showed that there were no significant differences in current suicidal ideation based on race, but found 
variations based on socioeconomic status. ${ }^{31}$ However, our finding is consistent with the rate of suicide by race/ethnicity among the general cisgender U.S. population; in 2017, the rate of suicide among Black individuals was significantly lower $(6.61 / 100,000)$ than that among White individuals $(15.85 /$ $100,000){ }^{32}$

Epidemiological studies on suicidal ideation exploring racial differences have shown that there are differential interaction effects that exist in the contribution of psychiatric conditions, socioeconomic status, and race to suicidal ideation. ${ }^{33-35}$ Furthermore, it has also been documented within mental health research that Black individuals tend to underreport their own mental health needs when self-reporting, and as such, may require specific and sensitive measurements that can accurately capture suicidal ideation. ${ }^{36}$ Future research must address these inconsistencies and consider interpreting our findings of suicidal ideation specific to race in contrast to the existing literature.

In addition, our findings highlight suicidal ideation among transgender women who are currently or have ever experienced homelessness. Mental health services provided in homeless shelters should consider the possibility of suicidal ideation when screening for mental health in this population. Moreover, as homelessness is a form of social marginalization that often stems from being ejected or removed from home,${ }^{37}$ there is a greater need to address this social determinant of suicidal ideation through parent-focused interventions. Previous studies among LGBT youths and trans women of color have shown that family conflict related to their sexual and/or gender identity was a primary reason for homelessness. ${ }^{37-39}$ As such, parental-focused interventions should highlight the consequences of ejection from home and unsupportiveness about youth's transgender identity.

Lastly, our study also highlights the need for future research focused on the impact of chosen families, often defined as a group of people who one considers as family despite no biological or legal connection. ${ }^{40}$ A recent study of LGBT youth found that those who lacked familial support were at high risk of experiencing mental health issues; however, those who received other forms of support in lieu of familial support (e.g., support from peers, mentors, romantic partners) reported lower levels of psychological stress compared with those who lacked support in any form. ${ }^{41}$ It is possible that YTW who experience unsupportive reactions from their biological parents may turn to chosen families for support. As such, research on chosen families as an avenue of intervention that could mitigate suicidal ideation among YTW is highly needed.

\section{Limitations}

There are several limitations to this study. First, data from this study came from an HIV risk reduction study and therefore eligibility criteria could limit the external validity of the findings. Second, this is a cross-sectional study where our ability to delineate causal inferences and interpretations is limited. Third, participants of our study may not be representative of the whole population of YTW as participants were only recruited in two major metropolitan cities. It should be noted that transgender people who live in states without antidiscrimination laws have higher rates of suicidality. ${ }^{42}$ Some of the variables included in this study asked about behaviors in the past (e.g., in the last 12 months), and as a result, some of the responses may be subject to recall bias. Lastly, suicidal ideation is multidimensional, and its complexity cannot be fully captured by a yes or no question. Additional research is recommended to understand how other factors (e.g., substance use, adverse childhood events, homelessness), as well as how these factors interact with parental support, may impact risk of suicidal ideation. Despite these limitations, there are currently no published studies that have specifically explored this topic among a sample of YTW exclusively, thus extending previous research that has conflated this group with other sexual and gender minority groups (e.g., conflating transgender women with MSM). ${ }^{43-45}$

\section{Conclusion}

This study sought to focus solely on characterizing the suicidal ideation experiences of racially and ethnically diverse YTW and highlights findings that have implications for future research directions and programmatic recommendations. These recommendations include: (1) addressing determinants of suicidal ideation among YTW starting with parent-focused interventions, particularly during a development milestone of disclosing transgender identity to parents; (2) screening for suicidal ideation in homeless shelters providing services for transgender women; (3) conducting further research on the role that chosen families may have in providing support to and mitigating suicidal ideation for YTW when biological and legal parents are absent or unsupportive; (4) conducting research that aims to understand and provide support to parents (especially mothers) who experience difficulty accepting the gender identity of their transgender children; and (5) conducting research that aims to understand and address open expressions of transgenderspecific prejudice and rejection among parents of transgender children.

\section{Disclaimer}

The content is solely the responsibility of the authors and does not necessarily represent the official views of the National Institute of Mental Health or the National Institutes of Health.

\section{Author Disclosure Statement}

No competing financial interests exist.

\section{Funding Information}

This project was supported by Award Number R01MH 094323 from the National Institute of Mental Health (NIMH; Principal Investigators: Drs. Garofalo and Mimiaga).

\section{References}

1. Downing JM, Przedworski JM: Health of transgender adults in the U.S., 2014-2016. Am J Prev Med 2018;55:336-344.

2. Mimiaga MJ, Hughto JMW, Biello KB, et al.: Longitudinal analysis of syndemic psychosocial problems predicting HIV risk behavior among a multicity prospective cohort of sexually active young transgender women in the United States. J Acquir Immune Defic Syndr 2019;81:184-192.

3. Reisner SL, Biello KB, White Hughto JM, et al.: Psychiatric diagnoses and comorbidities in a diverse, multicity cohort of 
young transgender women: Baseline findings from Project LifeSkills. JAMA Pediatr 2016;170:481-486.

4. Grossman AH, Park JY, Russell ST: Transgender youth and suicidal behaviors: Applying the interpersonal psychological theory of suicide. J Gay Lesbian Ment Health 2016;20: 329-349.

5. Perez-Brumer A, Day JK, Russell ST, Hatzenbuehler ML: Prevalence and correlates of suicidal ideation among transgender youth in California: Findings from a representative, population-based sample of high school students. J Am Acad Child Adolesc Psychiatry 2017;56:739-746.

6. James SE, Herman JL, Rankin S, et al.: The Report of the 2015 U.S. Transgender Survey. Washington, DC: National Center for Transgender Equality, 2016.

7. Alvarez EC, Kawachi I, Romani JR: Family social capital and health $-\mathrm{A}$ systematic review and redirection. Sociol Health Illn 2017;39:5-29.

8. Resnick MD, Bearman PS, Blum RW, et al.: Protecting adolescents from harm. Findings from the National Longitudinal Study on Adolescent Health. JAMA 1997;278:823-832.

9. Bouris A, Guilamo-Ramos V, Pickard A, et al.: A systematic review of parental influences on the health and wellbeing of lesbian, gay, and bisexual youth: Time for a new public health research and practice agenda. J Prim Prev 2010;31:273-309.

10. Ryan C, Huebner D, Diaz RM, Sanchez J: Family rejection as a predictor of negative health outcomes in White and Latino lesbian, gay, and bisexual young adults. Pediatrics 2009;123:346-352.

11. Ryan C, Russell ST, Huebner D, et al.: Family acceptance in adolescence and the health of LGBT young adults. J Child Adolesc Psychiatr Nurs 2010;23:205-213.

12. Simons L, Schrager SM, Clark LF, et al.: Parental support and mental health among transgender adolescents. J Adolesc Health 2013;53:791-793.

13. Veale JF, Peter T, Travers R, Saewyc EM: Enacted stigma, mental health, and protective factors among transgender youth in Canada. Transgend Health 2017;2:207-216.

14. Grossman AH, D’Augelli AR: Transgender youth and lifethreatening behaviors. Suicide Life Threat Behav 2007;37: 527-537.

15. Seibel BL, de Brito Silva B, Fontanari AMV, et al.: The impact of the parental support on risk factors in the process of gender affirmation of transgender and gender diverse people. Front Psychol 2018;9:399.

16. Kuhns LM, Mimiaga MJ, Reisner SL, et al.: Project LifeSkills-A randomized controlled efficacy trial of a culturally tailored, empowerment-based, and group-delivered HIV prevention intervention for young transgender women: Study protocol. BMC Public Health 2017;17:713.

17. Garofalo R, Kuhns LM, Reisner SL, et al.: Efficacy of an empowerment-based, group-delivered HIV prevention intervention for young transgender women: The Project LifeSkills randomized clinical trial. JAMA Pediatr 2018;172: 916-923.

18. Wilson EC, Chen YH, Arayasirikul S, et al.: The impact of discrimination on the mental health of trans*female youth and the protective effect of parental support. AIDS Behav 2016;20:2203-2211.

19. Le V, Arayasirikul S, Chen YH, et al.: Types of social support and parental acceptance among transfemale youth and their impact on mental health, sexual debut, history of sex work and condomless anal intercourse. J Int AIDS Soc 2016;19:20781.
20. Baker KE: Findings from the Behavioral Risk Factor Surveillance System on health-related quality of life among US transgender adults, 2014-2017. JAMA Intern Med 2019;179:1141-1144.

21. Nuttbrock L, Bockting W, Rosenblum A, et al.: Gender abuse and major depression among transgender women: A prospective study of vulnerability and resilience. Am J Public Health 2014;104:2191-2198.

22. Steinberg L, Duncan P: Work group IV: Increasing the capacity of parents, families, and adults living with adolescents to improve adolescent health outcomes. J Adolesc Health 2002;31:261-263.

23. Restar A, Jin H, Breslow AS, et al.: Developmental milestones in young transgender women in two American cities: Results from a racially and ethnically diverse sample. Transgend Health 2019;4:162-167.

24. Puckett JA, Woodward EN, Mereish EH, Pantalone DW: Parental rejection following sexual orientation disclosure: Impact on internalized homophobia, social support, and mental health. LGBT Health 2015;2:265-269.

25. Bauer GR, Scheim AI, Pyne J, et al.: Intervenable factors associated with suicide risk in transgender persons: A respondent driven sampling study in Ontario, Canada. BMC Public Health 2015;15:525.

26. Hill DB, Menvielle E: "You have to give them a place where they feel protected and safe and loved": The views of parents who have gender-variant children and adolescents. J LGBT Youth 2009;6:243-271.

27. Kuvalanka KA, Weiner JL, Mahan D: Child, family, and community transformations: Findings from interviews with mothers of transgender girls. J GLBT Fam Studies 2014;10:354-379.

28. Ishii Y: Rebuilding relationships in a transgender family: The stories of parents of Japanese transgender children. J GLBT Fam Studies 2018;14:213-237.

29. Lorenzo-Luaces L, Phillips JA: Racial and ethnic differences in risk factors associated with suicidal behavior among young adults in the USA. Ethn Health 2013;19: $458-477$.

30. Kota KK, Salazar LF, Culbreth RE, et al.: Psychosocial mediators of perceived stigma and suicidal ideation among transgender women. BMC Public Health 2020;20:125.

31. Testa RJ, Michaels MS, Bliss W, et al.: Suicidal ideation in transgender people: Gender minority stress and interpersonal theory factors. J Abnorm Psychol 2017;126:125136.

32. National Center for Injury Prevention and Control: Data \& Statistics Fatal Injury Report for 2017. Atlanta, GA: Centers for Disease Control and Prevention. Available at https:// www.cdc.gov/injury/wisqars/fatal.html Accessed August 3, 2020.

33. Gomez J, Miranda R, Polanco L: Acculturative stress, perceived discrimination, and vulnerability to suicide attempts among emerging adults. J Youth Adolesc 2011;40:14651476.

34. Castle K, Conner K, Kaukeinen K, Tu X: Perceived racism, discrimination, and acculturation in suicidal ideation and suicide attempts among Black young adults. Suicide Life Threat Behav 2011;41:342-351.

35. Assari S, Moghani Lankarani M, Caldwell CH: Discrimination increases suicidal ideation in Black adolescents regardless of ethnicity and gender. Behav Sci (Basel) 2017;7:75.

36. Gibbs JT. African-American suicide: A cultural paradox. Suicide Life Threat Behav 1997;27:68-79. 
37. Vandemark LM: Promoting the sense of self, place, and belonging in displaced persons: The example of homelessness. Arch Psychiatr Nurs 2007;21:241-248.

38. Robinson BA: Conditional families and lesbian, gay, bisexual, transgender, and queer youth homelessness: Gender, sexuality, family instability, and rejection. J Marriage Fam 2018;80:383-396.

39. Koken JA, Bimbi DS, Parsons JT: Experiences of familial acceptance-rejection among transwomen of color. J Fam Psychol 2009;23:853-860.

40. Dewaele A, Cox N, Van den Berghe W, Vincke J: Families of choice? Exploring the supportive networks of lesbians, gay men, and bisexuals. J Appl Soc Psychol 2011;41:312331.

41. McConnell EA, Birkett M, Mustanski B: Families matter: Social support and mental health trajectories among lesbian, gay, bisexual, and transgender youth. J Adolesc Health 2016;59:674-680.

42. Gleason HA, Livingston NA, Peters MM, et al.: Effects of state nondiscrimination laws on transgender and gendernonconforming individuals' perceived community stigma and mental health. J Gay Lesbian Ment Health 2016;20: $350-362$.
43. Liu RT, Mustanski B: Suicidal ideation and self-harm in lesbian, gay, bisexual, and transgender youth. Am J Prev Med 2012;42:221-228.

44. Mustanski BS, Garofalo R, Emerson EM: Mental health disorders, psychological distress, and suicidality in a diverse sample of lesbian, gay, bisexual, and transgender youths. Am J Public Health 2010;100:2426-2432.

45. Skerrett DM, Kõlves K, De Leo D: Are LGBT populations at a higher risk for suicidal behaviors in Australia? Research findings and implications. J Homosex 2015;62:883-901.

Address correspondence to: Harry Jin, PhD, MPH Department of Epidemiology Brown University School of Public Health 121 South Main Street Second Floor Reception Providence, RI 02903

USA

E-mail: harry_jin@brown.edu 